\title{
PERAMALAN PERMINTAAN PRODUK SALE PISANG PADA INDUSTRI "SAHABAT" DI DUSUN CIJOHO DESA MARGAJAYA KECAMATAN SUKADANA KABUPATEN CIAMIS
}

\author{
FORECASTING DEMAND FOR SALE BANANA PRODUCTS IN THE "SAHABAT" \\ INDUSTRY IN CIJOHO HAMLET, MARGAJAYA VILLAGE, SUKADANA \\ SUBDISTRICT, CIAMIS DISTRICTS.
}

\author{
NISA APRILIANTI ${ }^{1 *}$, IWAN SETIAWAN ${ }^{2}$, MUHAMAD NURDIN YUSUF $^{1}$ \\ ${ }^{1}$ Fakultas Pertanian Universitas Galuh \\ ${ }^{2}$ Fakultas Pertanian Universitas Padjajaran \\ *Email: nisaaprilianti57@gmail.com
}

\begin{abstract}
ABSTRAK
Perkembangan industri sale pisang yang ada di Desa Margajaya cukup penting dan menarik untuk diteliti, Sahabat merupakan industri yang berdiri relatif baru dengan memproduksi sale pisang yang cukup besar, jumlah penjualan produk sale pisang pada industri Sahabat belum efesien, karena produk yang dijual sering dikembalikan dalam jumlah cukup banyak oleh reseller. Penelitian ini bertujuan mengetahui ramalan permintaan produk sale pisang pada industri "Sahabat" di Dusun Cijoho Desa Margajaya Kecamatan Sukadana Kabupaten Ciamis pada bulan Maret samapai Desember tahun 2020. Penelitian ini dilaksanakan pada bulan Februari 2020. Responden dalam penelitian ini adalah pemilik agroindustri "Sahabat". Jenis penelitian yang digunakan adalah penelitian kuantitatif dan metode penelitian yang digunakan yaitu data primer dan data sekunder. Analisis yang digunakan adalah Single moving average (Rata-rata bergerak tunggal). Hasil penelitian menunjukkan bahwa dengan metode single moving average (rata-rata bergerak) untuk Forecast adalah 12.744 bungkus, dengan Mean Absolute Deviation sebesar 1.639 dan Mean Squared Error sebesar 7.658. Hasil ramalan pada bulan Maret dapat dihasilkan pula hasil peramalan atau perkiraan pada tahun 2020.
\end{abstract}

Kata Kunci: Peramalan, Permintaan, Rata-rata bergerak tunggal, MAD, MSE.

\begin{abstract}
The development of the banana sale industry in Margajaya Village is quite important and interesting to research, Sahabat is an industry that has been established relatively recently by producing a sizeable sale of bananas, the number of sales of banana sale products in the "Sahabat" industry is not efficient, because the products being sold are often returned in large quantities by resellers. This study aims to determine the forecasting of demand for sale banana products in the "Sahabat" Industry in Cijoho Hamlet Margajaya Village Sukadana Subdistrict Ciamis Districts in March to December 2020. This research was conducted in February 2020. Respondents in this study are owners of the agroindustry "Sahabat". This type of research is quantitative research and the research method used is primary data and secondary data.The analysis used is the single moving average. The results showed that the single moving average method (moving average) for the Forecast was 12,744 packs, with Mean Absolute Deviation of 1,639 and Mean Squared Error of 7,658. Forecast results in March can also produce forecast or forecast results in 2020.
\end{abstract}

Keywords: Forecasting, Demand, Single moving average, MAD, MSE.

\section{PENDAHULUAN}

Ketelitian dalam memenuhi

persediaan produk kepada konsumen merupakan salah satu langkah penting dalam proses berbisnis dalam bentuk penjualan dan pembelian, Ristono (2009) 
dalam Nurfawid (2018).

Peramalan (Forecasting) adalah suatu seni untuk memperkirakan apa yang akan terjadi dimasa yang akan datang dengan menggunakan data-data dari masa lalu, sehingga melalui peramalan bisa terjadi kemungkinan kejadian yang tidak sesuai dengan tujuan yang di inginkan. Hal ini sejalan menurut penelitian, Arie (2010), Ishak (2010), Murahartawaty (2009), Manahan (2014), Hasibuan dalam Sarini (2013), Heizer (2015), Menurut Kotler dalam Setyawan (2016).

Salah satu hal supaya dapat mewujudkan apa yang diinginkan tersebut dengan cara memprediksi atau meramal (forecasting) banyaknya penjualan atau permintaan konsumen terhadap produk atau barang yang diproduksi, (Indriastiningsih, 2016)

Agrondustri yang memproduksi sale pisang di Kabupaten Ciamis, tercatat pada Kantor Dinas Koperasi, UMKM, Perindustrian dan Perdagangan Kabupaten Ciamis Tahun 2020, tecatat sebanyak 7 agroindustri dan agroindustri "Sahabat" termasuk dalam salah satunya. Hal tersebut menunjukkan bahwa agroindusti sale pisang "Sahabat" bersaing dengan beberapa agroindustri sale pisang, bahkan masih banyak agroindustri sale pisang yang belum terdaftar di Dinas Koperasi
UMKM, Perindustrian dan Perdagangan Kabupaten Ciamis, yang merupakan pesaing baik dari segi kualitas produk, kuantitas, dan kemampuan memenuhi permintaan konsumen.

Semakin berkembangnya industri sale pisang yang ada di Kabupaten Ciamis, maka dapat menambah lapangan kerja baru dengan kata lain, dapat mengurangi jumlah pengangguran, karena pada setiap industri memerlukan tenaga kerja baik dalam jumlah sedikit maupun besar, sehingga tingkat produktivitas industri semakin tinggi.

Perkembangan industri sale pisang yang ada di Desa Margajaya cukup penting dan menarik untuk diteliti, Sahabat merupakan industri yang berdiri relatif baru dengan memproduksi sale pisang yang cukup besar di Desa Margajaya, jumlah penjualan produk sale pisang pada industri "Sahabat" belum efesien, karena produk yang dijual sering dikembalikan dalam jumlah cukup banyak oleh reseller. Pengembalian tersebut diakibatkan oleh besarnya jumlah produk, namun tidak diikuti oleh jumlah permintaan yang sebanding.

\section{METODE PENELITIAN}

Jenis penelitian yang dilakukan adalah studi kasus di agroindustri sale pisang "Sahabat" di Dusun Cijoho Desa 
Margajaya Kecamatan Sukadana Kabupaten Ciamis. Menurut Aziz (2003), studi kasus yaitu metode penelitian mengenai individu, atau unit sosial tertentu dalam jangka waktu yang ditentukan atau berupa kejadian yang ada dan terjadi nyata dalam konteks kehidupan.

Data yang digunakan dalam penelitian ini bersumber dari data primer dan data sekunder. Pengumpulan data primer dilakukan dengan cara teknik observasi dengan tujuan untuk memperoleh data produksi sale pisang pada bulan Maret 2020 sampai Desember 2020, selanjutnya teknik wawancara langsung pada pemilik industri "Sahabat" dengan menggunakan daftar pertanyaan. Data sekunder diperoleh dari berbagai literatur, dan beberapa instansi yang terkait yang dalam kegiatan penilitian.Tujuan penelitian untuk mengetahui : (1) Pertumbuhan pemintaan sale pisang Sahabat selama bulan Maret sampai dengan bulan Desember tahun 2020. (2) Perkembangan permintaan sale pisang Sahabat untuk 10 bulan kedepan. Dianalisis secara deskriptif menggunakan metode Moving Average yang termasuk dalam time series model yang merupakan metode peramalan kuntitatif dengan menggunakan waktu sebagai dasar peramalan. Adapun rumus yang diguakan adalah.

$\mathrm{St}+1=\frac{X t+X t-1+\cdots X t-n+1}{n}$

Keterangan :

St $+1=$ Forecast untuk period ke $\mathrm{t}+1$.

$\mathrm{Xt}=$ Data pada periode $\mathrm{t}$.

$\mathrm{n}=$ Jangka waktu Moving average

Mengukur error (kesalahan)

Forecast biasanya digunakan Mean Absolute Deviation (MAD) dan Mean Square Error (MSE). Mean Absolute Deviation (MAD) adalah rata-rata absolute dari kesalahan meramal, tanpa memedulikan tanda negatif atau positif. Secara matematis, MAD dirumuskan :

$$
\mathrm{MAD}=\sum(\mathrm{At}-\mathrm{Ft})
$$

Keterangan:

At $=$ Permintaan Aktual pada periode $-\mathrm{t}$.

$\mathrm{Ft}=$ Peramalan Permintaan (Forecast)

pada periode-t.

Rata-rata Kuadrat Kesalahan Mean Square Error (MSE). MSE dihitung dengan menjumlahkan kuadrat semua kesalahan peramalan pada setiap periode dan membaginya dengan jumlah periode peramalan. Secara matematis, MSE dirumuskan sebagai berikut ( Nasution dalam Gusdian, 2016 ) 


$$
\operatorname{MSE}=\frac{\sum(\mathrm{At}-\mathrm{Ft})^{2}}{\mathrm{n}}
$$

Keterangan :

$$
\begin{aligned}
& \text { At }=\text { Permintaan Aktual pada } \\
& \text { periode }-\mathrm{t} \text {. } \\
& \mathrm{Ft}=\text { Peramalan Permintaan } \\
& (\text { Forecast }) \text { pada periode-t. } \\
& \mathrm{n}=\text { Jumlah periode peramalan } \\
& \text { yang terlibat. }
\end{aligned}
$$

\section{HASIL DAN PEMBAHASAN}

\section{Produksi Sale Pisang "Sahabat.}

Proses pembuatan sale pisang pada agroindustri sale pisang "Sahabat"di Desa Margajaya Kecamatan Sukadana Kabupaten Ciamis meliputi, pengupasan, penjemuran, penggorengan dan pengemasan. Agroindustri "Sahabat" memproduksi sale pisang yang jumlahnya berfluktasi. Adapun data permintaan agroindustri sale pisang "Sahabat" adalah adalah seperti pada Gambar 1.

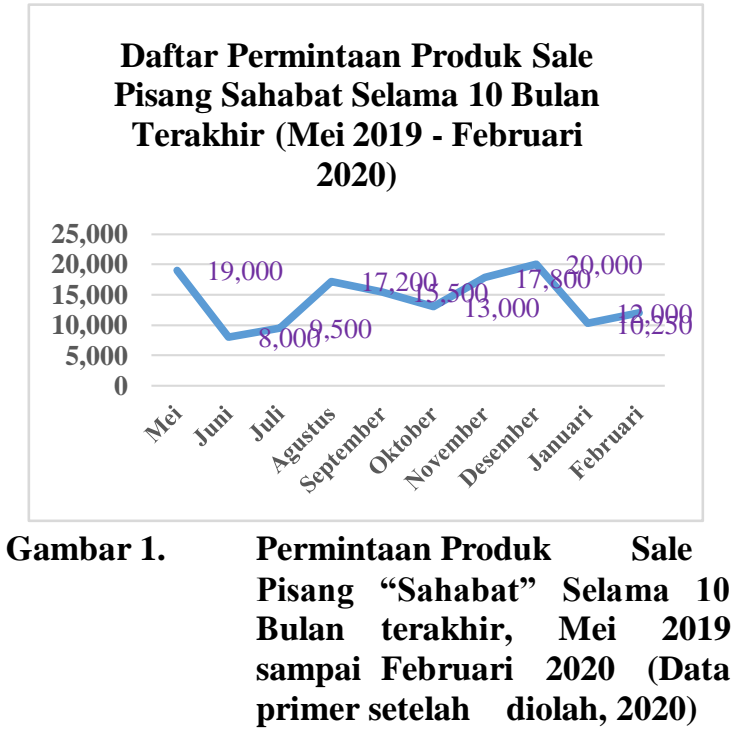

Dari data diatas menunjukan data permintaan sale pisang pada agroindustri "Sahabat" setiap bulannya mengalami fluktuasi dari periode Mei 2019 sampai Februari 2020. Permintaan sale pisang terjadi ini disebabkan maraknya usaha sale pisang dikota Ciamis yang artinya persaingan semakin banyak sehingga permintaan produk sale pisang pada agroindustri "Sahabat" menjadi tidak konsisten.

Permintaan tertingngi terdapat pada bulan Desember yaitu sebanyak 20.000 bungkus, hal tersebut terjadi di karenakan mendekati taun baru, dimana permitaan selalu tinngi karena banyak orang berwisata untuk merayakan taun baru, sehingga banyak konsumen yang berhenti di tempat pembelian oleh-oleh untuk berbelanja sehingga menyebabkan permintaan produk tinggi. Permintaan terendah pada bulan Juni disebabkan karena kurangnya tanggal merah karena sasaran agroindustri sale pisang "Sahabat" adalah parawisata.

\section{Peramalan Permintaan Sale Pisang "Sahabat".}

Metode Single Moving average atau metode rata-rata bergerak adalah metode yang banyak digunakan untuk menentukan trend dari suatu deret waktu. Dengan menggunakan metode rata-rata bergerak. 
Pada metode ini menggunakan data paling sedikit 3 periode, tetapi yang sering digunakan antara lain: 3 periode, dan 5 periode.

Tabel 2.Peramalan Single Moving Average 3 Bulan dan 5

\begin{tabular}{lccc}
\hline \multicolumn{1}{c}{ Priode (Bulan) } & Permintaan (Bks) & $\begin{array}{c}\text { MA 3 } \\
(\mathbf{B k s})\end{array}$ & $\begin{array}{c}\text { MA 5 } \\
(\text { Bks) }\end{array}$ \\
\hline Mei 2019 & 19.000 & - & - \\
Juni 2019 & 8.000 & - & - \\
Juli 2019 & 9.500 & - & - \\
Agustus 2019 & 17.200 & 12.167 & - \\
September 2019 & 15.500 & 11.567 & - \\
Oktober 2019 & 13.000 & 14.067 & 13.840 \\
November 2019 & 17.800 & 15.233 & 12.640 \\
Desember 2019 & 20.000 & 15.433 & 14.600 \\
Januari 2020 & 10.250 & 16.933 & 16.700 \\
Februari 2020 & 12.000 & 16.017 & 15.310 \\
Maret 2020 & 14.083 & 14.083 & 14.610 \\
April 2020 & 12.111 & 12.111 & 14.827 \\
Mei 2020 & 12.731 & 12.731 & 13.689 \\
Juni 2020 & 12.975 & 12.975 & 12.235 \\
Juli 2020 & 12.606 & 12.605 & 12.780 \\
Agustus 2020 & 12.771 & 12.770 & 12.901 \\
September 2020 & 12.784 & 12.783 & 12.639 \\
Oktober 2020 & 12.720 & 12.720 & 12.773 \\
November 2020 & 12.758 & 12.758 & 12.771 \\
Desember 2020 & 12.754 & 12.753 & 12.728 \\
\hline Sumber & & &
\end{tabular}

Sumber : $\quad$ Data primer setelah diolah, 2020.

Tabel 2 menunjukan bahwa dapat diketahui ramalan atau perkiraan sale pisang "Sahabat" pada bulan Maret 2020 sebesar 14.083. Ramalan pada bulan Maret 2020 dihasilkan dari perhitungan rata-rata bergerak dalam 3 bulan moving average.
Menghitung 3 Bulan Moving Average Mean Sqcuared Error (MSE) Dan 5 Bulan Moving Average Mean Absolute Deviation (MAD).

Nilai error yang asli biasanya tidak dirata-ratakan sebagai ukuran besar kecilnya error, sebab ada yang positif dan ada yang negatif. Sehingga kalau dijumlah error pasti akan kecil, sebab error yang positif akan dikurangi dengan error yang negatif dapat diterlihat pada tabel 
Tabel 3. Menghitung Mean Sqcuared Error (MSE) dan Mean Absolute Error (MAE).

\begin{tabular}{|c|c|c|c|c|c|c|c|c|c|}
\hline $\begin{array}{l}\text { Priode } \\
\text { (Bulan) }\end{array}$ & Permintaan & $\begin{array}{l}\text { MA 3 } \\
\text { (Bks) }\end{array}$ & $\begin{array}{c}\text { Error } \\
\text { MA }\end{array}$ & $\begin{array}{c}\text { Absolute } \\
\text { MA } 3\end{array}$ & MSE & $\begin{array}{l}\text { MA 5 } \\
\text { (Bks) }\end{array}$ & Error & $\begin{array}{c}\text { Absolute } \\
\text { MA } 5\end{array}$ & Error $^{2}$ \\
\hline Mei 2019 & 19.000 & - & - & - & - & - & - & - & - \\
\hline Juni 2019 & 8.000 & - & - & - & - & - & - & - & - \\
\hline Juli 2019 & 9.500 & - & - & - & - & - & - & - & - \\
\hline $\begin{array}{l}\text { Agustus } \\
2019\end{array}$ & 17.200 & 12.167 & 5.033 & 5.033 & 25.334 .444 & - & - & - & - \\
\hline $\begin{array}{l}\text { September } \\
2019\end{array}$ & 15.500 & 11.567 & 3.933 & 3.933 & 15.471 .111 & - & - & - & - \\
\hline $\begin{array}{l}\text { Oktober } \\
2019\end{array}$ & 13.000 & 14.067 & 1.067 & 1.067 & 1.137 .778 & 13.840 & -840 & 840 & 705.600 \\
\hline $\begin{array}{l}\text { November } \\
2019\end{array}$ & 17.800 & 15.233 & 2.567 & 2.567 & 6.587 .778 & 12.640 & 5.160 & 5.160 & 26.625 .600 \\
\hline $\begin{array}{l}\text { Desember } \\
2019\end{array}$ & 20.000 & 15.433 & 4.567 & 4.567 & 20.854 .444 & 14.600 & 5.400 & 5.400 & 29.160 .000 \\
\hline $\begin{array}{l}\text { Januari } \\
2020\end{array}$ & 10.250 & 16.933 & $6.683^{-}$ & 6.683 & 44.666 .944 & 16.700 & $6.450^{-}$ & 6.450 & 41.602 .500 \\
\hline $\begin{array}{l}\text { Februari } \\
2020\end{array}$ & 12.000 & 16.017 & $4.017^{-}$ & 4.017 & 16.133 .611 & 15.310 & $3.310^{-}$ & 3.310 & 10.956 .100 \\
\hline $\begin{array}{l}\text { Maret } \\
2020\end{array}$ & 14.083 & 14.083 & 0,00 & 0,00 & 0,00 & 14.610 & -527 & 527 & 277.729 \\
\hline April & & & 0,00 & 0,00 & 0,00 & & - & & \\
\hline 2020 & 12.111 & 12.111 & & & & 14.827 & 2.716 & 2.716 & 7.374 .483 \\
\hline Mei 2020 & 12.731 & 12.731 & 0,00 & 0,00 & 0,00 & 13.689 & -958 & 958 & 917.764 \\
\hline Juni 2020 & 12.975 & 12.975 & 0,00 & 0,00 & 0,00 & 12.235 & 740 & 740 & 547.600 \\
\hline Juli 2020 & 12.606 & 12.605 & 0,00 & 0,00 & 0,00 & 12.780 & -174 & 174 & 30.276 \\
\hline Agustus & & & 0,00 & 0,00 & 0,00 & & & & \\
\hline $\begin{array}{l}2020 \\
\text { September }\end{array}$ & 12.771 & 12.770 & 0,00 & 0,00 & 0,00 & 12.901 & -130 & 130 & 16.952 \\
\hline 2020 & 12.784 & 12.783 & & & & 12.639 & 145 & 145 & 21.083 \\
\hline Oktober & & & 0,00 & 0,00 & 0,00 & & & & \\
\hline $\begin{array}{l}2020 \\
\text { November }\end{array}$ & 12.720 & 12.720 & 0,00 & 0,00 & 0,00 & 12.773 & -53 & 53 & 2.852 \\
\hline $\begin{array}{l}2020 \\
\text { Desember }\end{array}$ & 12.758 & 12.758 & 0,00 & 0.00 & 0,00 & 12.771 & -13 & 13 & 174 \\
\hline 2020 & 12.754 & 12.753 & & & & 12.728 & 26 & 26 & 686 \\
\hline Total & 270.543 & & & 27.867 & 130.186.1 & & & 26.643 & 118.239 \\
\hline Average & $13,527,15$ & & & 1.639 & 7.658 & & & 1.776 & 7.882 \\
\hline $\begin{array}{l}\text { Nex } \\
\text { period } \\
\text { forecast }\end{array}$ & & 12.744 & & (MAD) & (MSE) & 12.754 & & (MAD) & (MSE) \\
\hline
\end{tabular}

Sumber : Data primer setelah diolah, 2020

Hasil perhitungan ramalan penjualan sale pisang agroindustri "Sahabat" dengan metode single moving averages 3 bulanan yaitu 12.744, dan jumlah forcast 3 bulan forcast sebesar 27.867. Tetapi kalau 5 bulan moving average 5 bulanan yaitu 12.754 dan jumlah forcast 5 bulan forcast sebesar 26.643. 
Tabel 4. Perbandingan error antara 3 bulan dan 5 bulan moving average.

\begin{tabular}{llll} 
3 Bulan Moving Average & Forecast $=12.744$ & MAD $=1.639$ & MSE $=7.658$ \\
\hline 5 Bulan Moving Average & Forecast $=12.754$ & MAD $=1.776$ & MSE $=7.882$ \\
\hline Sumber
\end{tabular}

Sumber : Data primer setelah diolah, 2020

Forcast 3 bulan moving average lebih kecil dari pada forcast 5 bulan, menghasilkan error yang lebih rendah dari pada forcast 5 bulan. Berarti forecast 3 sehingga metode 3 Bulan Moving Average bulan moving average penyimpangannya lebih tepat.

\section{bulan moving average penyimpangannya}

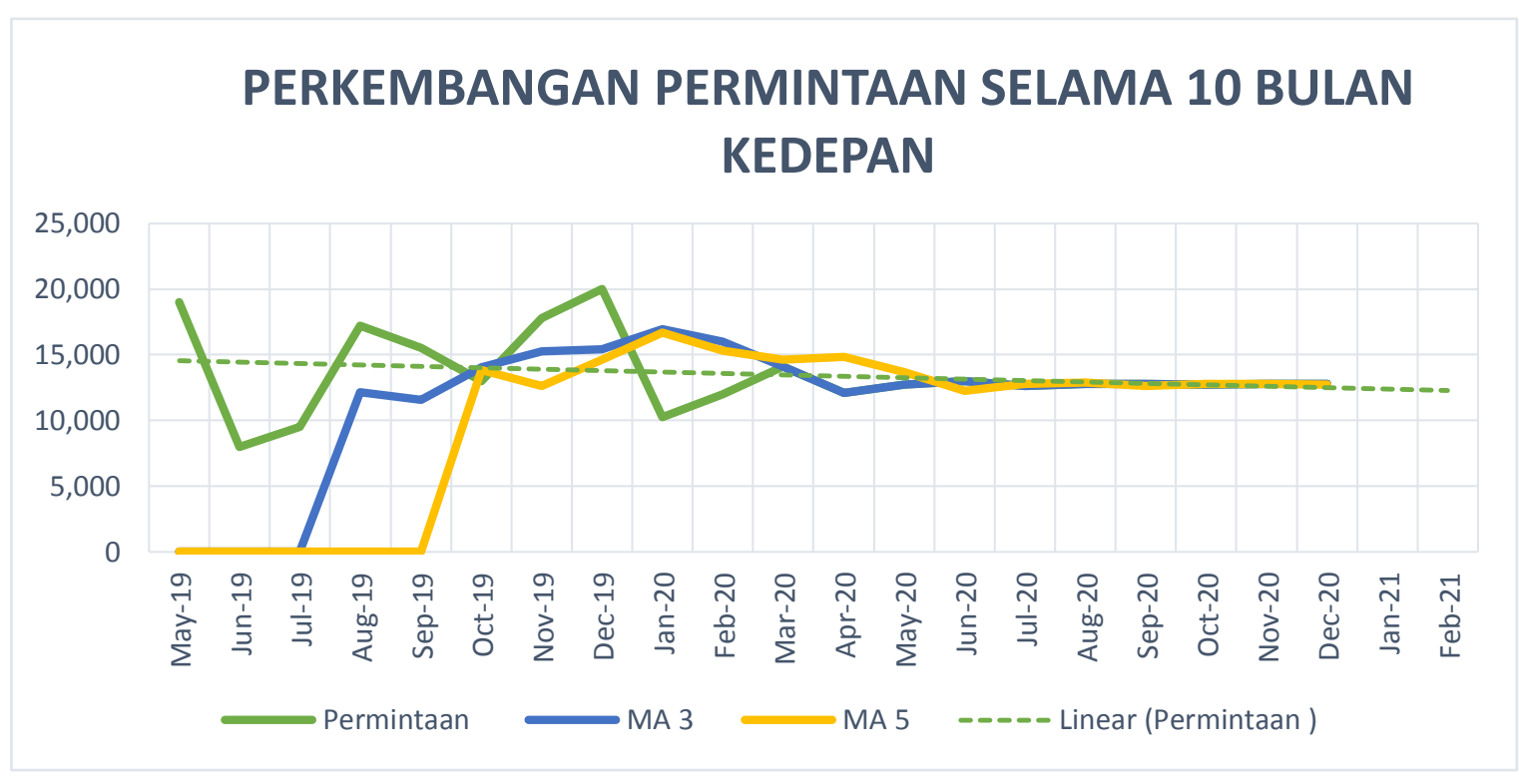

Gambar 2. Perkembangan Permintaan, Mei 2019 sampai Desember 2020 (Data primer setelah diolah, 2020).

Data menunjukkan bahwa data permintaaan produk sale pisang "Sahabat" selama 20 bulan ( Mei 2019 - Desember 2020 ) hasil data ramalan yang diperoleh berfluktuasi. Data ramalan 10 bulan kedepan (Maret 2020 - Desember 2020) mununjukan bahawa permintaan sale pisang "Sahabat" mengalami penurunan secara garis linear.

\begin{abstract}
KESIMPULAN DAN SARAN

\section{Kesimpulan.}

1. Hasil ramalan atau perkiraan pertumbuhan permintaan sale pisang "Sahabat" selama bulan Maret 2019 sampai dengan bulan Desember 2020 dengan metode single moving average (rata-rata bergerak) untuk Forecast $=12.744$ bungkus, dengan
\end{abstract}


mean absolute error 1.639 dan mean squared 7.658 .

2. Hasil data peramalan perkembangan permintaan sale pisang Sahabat mengalami fluktuasi yang menyebabkan gerakan data berkala tidak teratur yang disebabkan oleh peristiwa-peristiwa yang terjadi pada permintaan sale pisang "Sahabat" di reseller dan banyaknya persaingan sale pisang sehingga permintaan sale pisang "Sahabat" pun menurun.

\section{Saran}

Untuk meningkatkan permintaan akan produk sale pisang "Sahabat" maka diharapkan kepada pihak agroindustri agar lebih memperhatikan produk, baik dari segi kemasan, pemasaran ataupun promosi yang lebih menarik konsumen.

Diharapkan kepada pihak agroindustri agar menjaga keunggulan produk dan mampu berusaha lebih baik lagi untuk bersaing dipasaran supaya tidak terjadi penurunan permintaan. Serta mampu bersaing dibidang harga dengan kondisi produk yang terjangkau maka akan semakin banyak permintaan yang terjadi.

\section{DAFTAR PUSTAKA}

Abdul Aziz SR, 2003, Menyusun Rancangan Penelitian Kualitatif dalam Analis data Penelitian
Kualitatif, Jakarta : Raja Grafindo Persada

Arie, R.W. dan Salvador, M.P. 2010. Studi Analisis Peramalan dengan Metode Deret berkala. Jurnal Widya teknikal. Vol.18 (2):1-6.

Dinas Koperasi UMKM, Perindustrian dan Perdagangan Kabupaten Ciamis 2020. Daftar Industri Sale Pisang kabupaten Ciamis. Ciamis.

Gusdian, E. Abdul, M. Dan Arifuddin, L. 2016. Peramalan Permintaan

Produk Roti Pada Industri "Tiara Rizki" Di Kelurahan Boyaoge Kecamatan Tatanga

Kota Palu. Journal of Agrotekbis, 4(1): 97-105.

Heizer, J. dan Render, B. 2015. Manajemen Operasi, Manajemen Keberlangsungan dan Rantai Pasokan, Edisi 11, Alih Bahasa : Hirson, K. Ratna, S dan David, W. Penerbit Salemba Empat. Jakarta

Indriastiningsih, E. Dan Anita, O.T. 2016. Analisis Forecasting (Peramalan) Produk Keripik Pisang Kemasan Bungkus. Surakarta.Vol.9(3) : 129.

Ishak, Aulia, 2010, Manajemen Operasi, Edisi Pertama, Graha Ilmu, Yogyakarta

Manahan P. Dan Tampubolon. 2014. Manajen Operasional dan Rantai Pasok. Mitra Wacana Media. Jakarta.

Nasapi M, dkk. 2014. Peramalan Permintaan Susu Pasteurisasi Menggunakan Metode Jaringan Syaraf Tiruan dan Time Series (Studi Kasus di Koperasi Susu SAE Pujon, Malang). Jurnal EECCIS. 6(1) : 112.

Nufawid, A. 2018. Sistem Informasi Peramalan Penjualan Obat Menggunakan Metode Adaptive Response Rate 
Singel Exponential Smooting. Universita Jember.

Sariani, I. 2013. Analisis Peramalan Penjualan Dan Penggunaan Metode Linear Programming Dan Decision Tree Guna Mengoptimalkan Keuntungan Pada Pt Primajaya Pantes Garment. Jakarta.Journal The Winners. 14(2): 115
Setyawan, E. dkk. 2016. Analisis Peramalan (Forecasting) Produksi Karet (Hevea Brasiliensis) Di Pt Perkebunan Nusantara Ix Kebun Sukamangli Kabupaten Kendal. Jurnal Ilmu-ilmu Pertanian.12(2) $: 11-1$ 